\title{
Pancreatic ketoacidosis-a rare case report
}

\author{
Dhivahar G. ${ }^{1}$, Rajan P. ${ }^{2}$, Raghunath $D^{3}{ }^{3}$, Misra S. ${ }^{*}$ \\ DOI: https://doi.org/10.17511/ijmrr.2020.i01.21
}

1 Dhivahar G, Consultant, Critical Care Medicine, GEM Hospital and Research Center, Tamil Nadu, India.

2 Paresh Rajan, Registrar, Surgical Gastroenterology, GEM Hospital and Research Center, Tamil Nadu, India.

${ }^{3}$ Raghunath D., Consultant, Critical Care Medicine, GEM Hospital and Research Center, Tamil Nadu, India.

4* Shivanshu Misra, Consultant Surgical Gastroenterologist and Advanced Laparoscopic Surgeon, GEM Hospital and Research Center, Tamil Nadu, India.

Euglycemic Pancreatic Ketoacidosis is a syndrome of high anion gap acidosis in which the high anion gap is due to elevated serum ketone bodies comprising of acetone, aceto- acetate and beta hydroxyl-butyrate, due to increased peripheral adipose tissue breakdown by elevated serum lipase as a consequence of acute pancreatitis with normal blood glucose levels. There are multiple causes for ketonuria and/or ketonemia with or without acidosis like uncontrolled diabetes mellitus, usually of the insulin dependent type (diabetic ketoacidosis), lactic acidosis, prolonged starvation (starvation ketosis), ethanol ingestion (alcoholic ketoacidosis), sepsis, pregnancy and vomiting. Our patient was not a known diabetic and his blood glucose were always within normal limits, so this ketoacidosis cannot be attributed to Diabetes Mellitus. It cannot be attributed to starvation as our patient was not fasting when he got admitted and furthermore ketoacidosis is not a frequent manifestation of starvation adding to it that we transfused adequate amount of DNS and resumed oral intake during our observation period. It cannot be attributed to vomiting as our patient had only two episodes of vomiting. Our patient does not have any liver or kidney pathology and there is no history or evidence of alcohol intoxication. But, acute pancreatitis without diabetes-mellitus, causing ketoacidosis is a very rare presentation which is caused by high levels of pancreatic lipase in the circulation.

Keywords: Pancreatic ketoacidosis, Pancreatitis, Diabetes mellitus, Anion gap acidosis, Ketonuria, Ketonemia

\section{Corresponding Author}

Shivanshu Misra, Consultant Surgical Gastroenterologist and Advanced Laparoscopic Surgeon, , GEM Hospital and Research Center, , Tamil Nadu, India.

Email: shivanshu_medico@rediffmail.com
How to Cite this Article

To Browse

Dhivahar G, Rajan P, Raghunath D, Misra S.

Pancreatic ketoacidosis-a rare case report. Int J Med Res Rev. 2020;8(1):136-139.

Available From

https://ijmrr.medresearch.in/index.php/ijmrr/article/ view/1136

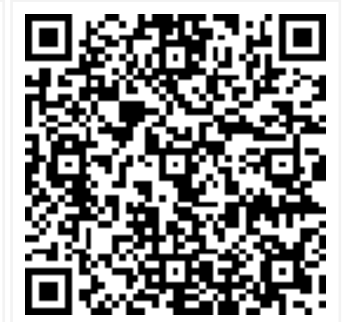

Manuscript Received 2020-01-10

Conflict of Interest No
Review Round 1 2020-01-20

Funding Nil

Review Round 2
2020-01-24
Ethical Approval
Yes

Review Round 2

Yes
Review Round 3

Plagiarism X-checker $6 \%$
Accepted 2020-01-27

Note

(c) 2020 by Dhivahar G, Paresh Rajan, Raghunath D., Shivanshu Misra and Published by Siddharth Health Research and Social Welfare Society. This is an Open Access article licensed under a Creative Commons Attribution 4.0 International License https://creativecommons.org/licenses/by/4.0/ unported [CC BY 4.0]. 


\section{Introduction}

Our patient was not a known diabetic and his blood glucose were always within normal limits, so this ketoacidosis cannot be attributed to Diabetes Mellitus. It cannot be attributed to starvation as our patient was not fasting when he got admitted and furthermore ketoacidosis is not a frequent manifestation of starvation adding to it that we transfused adequate amount of DNS and resumed oral intake during our observation period.

It cannot be attributed to vomiting as our patient had only two episodes of vomiting. Our patient does not have any liver or kidney pathology and there is no history or evidence of alcohol intoxication.

Eckerwall $\mathrm{G}$ et al, advocated a nutritional treatment regime in severe acute pancreatitis including a moderate and hypocaloric initial fluid resuscitation, parental nutrition as the preferred route for nutritional support and a non-strict glucose control, with an associated mortality of $17 \%$, indicates several modes of improving outcome [1].

In his report, Kabadi UM described three patients who manifested ketoacidosis at the time of presentation of acute pancreatitis. In none of these patients could ketoacidosis be attributed to any of the well-known pathogenetic factors such as ethanol, diabetes mellitus or prolonged starvation Therefore, he believe that pancreatic ketosis or ketoacidosis may be a distinct syndrome with ketogenesis being promoted and maintained by extremely high circulating pancreatic lipase concentrations. This was thereafter named "Kabadi syndrome", mimicking diabetic ketoacidosis $[2,3]$.

\section{Case Report}

A 13 years boy, known case of recurrent pancreatitis was admitted in ICU with complaints of acute onset severe upper abdominal pain, radiating to back which got mildly relieved by sitting up or stooping forward along with two episodes of bilious and nonprojectile vomiting. There was no history of fever, starvation, sepsis, alcohol intake or any liver or kidney pathology.

On examination patient was conscious, oriented but irritable, afebrile, dehydrated and dyspnoeic. Pulse rate was $116 / \mathrm{min}$; blood pressure was $130 / 82$ in right arm in supine position; respiratory rate was $36 / \mathrm{min}$. There were no signs of icterus, pallor, cyanosis, clubbing, lymphadenopathy and pedal
Edema. Diffuse upper abdominal tenderness was present with no guarding, rigidity and organomegaly. Other systemic examinations were within normal limits.

\section{Investigations all investigations were within normal limit}

Plasma acetone: Positive

Serum amylase: $187 \mathrm{U} / \mathrm{L}$

Serum lipase: 812 U/L

\section{Urine examination}

Acetone: Positive

Microscopic examination: within normal limit

\section{Arterial blood gas analysis}

PH: 7.11

Calcium: $4.18 \mathrm{mg} / \mathrm{dl}$

HCO3: $10.5 \mathrm{mmol} / \mathrm{L}$

Base: $-18.5 \mathrm{mmol} / \mathrm{L}$

Anion gap: $26.4 \mathrm{mmol} / \mathrm{L}$

CECT Abdomen: Edematous and enlarged pancreas with dilated pancreatic duct.

MRCP: Dilated pancreatic duct with long segment stricture in head region.

No divisum.

Treatment: We made a clinical diagnosis of acute pancreatitis with ketoacidosis. We kept the patient nil per oral for 12 hours and we started oral liquid diet after that along with pancreatic enzyme replacement of 10,000 units thrice daily.

We treated him with DNS infusion at the rate of $100 \mathrm{ml}$ per hour and intra-venous insulin infusion; Intra-venous infusion of dexmedetomidine at the rate of 0.2 microgram per $\mathrm{kg}$ per hour was started for abdominal pain which was slowly tapered off in the next 24 hours according to the patient's symptoms.

Four hourly monitoring of blood glucose, vitals and input-output charting was done (Table 1). Every 4 hourly arterial blood gas (ABG) analysis was done. After 24 hours hemogram with complete blood counts, serum electrolytes, Liver function test, serum creatinine, blood urea, plasma ketones and urine ketones were repeated (Table 2). 
Table-1: Four hourly monitoring of vital parameters and blood markers.

\begin{tabular}{|l|l|l|l|l|l|l|}
\hline & Pulse rate (per minute) & Blood Pressure $(\mathrm{mm}$ of $\mathrm{Hg})$ & PH (arterial) & Bicarbonate $(\mathrm{mmol} / \mathrm{L})$ & Anion gap $(\mathrm{mmol} / \mathrm{L})$ & Blood Glucose $\mathrm{Mg} / \mathrm{dL}$ \\
\hline At admission & 116 & $130 / 82$ & 7.11 & 10.5 & 26.5 & 110 \\
\hline After 4 hours 120 & $104 / 68$ & 7.12 & 11 & 25 & 140 \\
\hline At 8 hours & 108 & $110 / 72$ & 7.14 & 12.5 & 23.5 & 136 \\
\hline At 12 hours & 102 & $110 / 74$ & 7.20 & 15.5 & 21.5 & 148 \\
\hline At 16 hours & 90 & $116 / 70$ & 7.32 & 18.2 & 19.8 & 134 \\
\hline At 20 hours & 82 & 7.40 & 22.3 & 15.7 & 122 \\
\hline At 24 hours & 80 & $118 / 72$ & 7.44 & 24 & 12 & 114 \\
\hline
\end{tabular}

Table-2: Comparison of liver function tests

\begin{tabular}{|l|l|l|}
\hline & At Admission & \multicolumn{1}{|c|}{$\mathbf{2 4}$ hours after admission } \\
\hline Serum Lipase & $812 \mathrm{U} / \mathrm{L}$ & $133 \mathrm{U} / \mathrm{L}$ \\
\hline Serum Amylase & $187 \mathrm{U} / \mathrm{L}$ & $140 \mathrm{U} / \mathrm{L}$ \\
\hline Plasma ketones & Positive & Negative \\
\hline Urine ketones & Positive & Negative \\
\hline
\end{tabular}

Rest of the blood investigations were within normal limits.

\section{Discussion}

Prater J et al and Rawla P et al, studied Euglycemic diabetic ketoacidosis and diagnostic and therapeutic dilemmas associated with it. euglycemic diabetic ketoacidosis (EDKA) is a clinical triad comprising increased anion gap metabolic acidosis, ketonemia or ketonuria and normal blood glucose levels $<200$ $\mathrm{mg} / \mathrm{dL}$. This condition is a diagnostic challenge as euglycemia masquerades the underlying diabetic ketoacidosis. Thus, a high clinical suspicion is warranted, and other diagnosis ruled out. Thawabi $M$ et $a l$, in a similar study also saw a misleading presentation of diabetic ketoacidosis $[4,5,6]$.

Pillai etal reported a very similar case like us. Ketosis or ketoacidosis secondary to acute pancreatitis is a distinct, though previously unrecognised syndrome, induced and maintained by extremely high levels of pancreatic lipase in the circulation. Pancreatic lipase is responsible in induction of ketonaemia by promoting ketogenesis via peripheral adipose tissue breakdown.

Ketonaemia is well documented as a consequence of prolonged starvation, acute alcoholism, and uncontrolled diabetes mellitus. Euglycemic ketoacidosis due to pancreatitis is a very rare entity and Only very few cases have been reported worldwide. Similar results were also seen by Modi et al in their review on euglycemic diabetic ketoacidosis $[7,8]$.

Hurrell FE et al studied Beta-hydroxybutyrate
Concentrations in dogs with acute pancreatitis and without diabetes mellitus. They also found the same phenomenon occuring as pancreatic lipase was responsible in induction of ketonaemia by promoting ketogenesis via peripheral adipose tissue breakdown, without the blood glucose being high [9].

Kabadi described a syndrome, "pancreatic ketoacidosis" or the presence of ketonaemia in association with acute pancreatitis. In these patients, hyperglyca emia was not characteristically noted. In his report, he describe subjects in whom ketoacidosis was detected at the time of presentation with acute pancreatitis. Both of these subjects manifested simultaneous mild hyperglycaemia. There was no prior history of diabetes mellitus, nor did he require antidiabetic therapy following resolution of acute pancreatitis.

In none of these cases, ketoacidosis could be attributed to diabetes because ketonaemia persisted for several days despite attaining euglycaemia with insulin therapy in one and with appropriate therapy for acute pancreatitis in the other contrast to diabetic ketoacidosis (DKA) in which ketonaemia resolves within 48-72 hours. Ketoacidosis could not be attributed to ethanol either because serum ketone titers are frequently negative in this syndrome and ethanol was not an inducer of pancreatitis in one of the subjects.

Finally, starvation as a cause was least likely since starvation induces ketonuria rather than ketonaemia and hardly ever acidosis. Finally, mild hyperglycaemia has been documented to occur in acute pancreatitis. In addition, serum ketone titers declined in concurrence with lowering of serum lipase levels and became undetectable only following near normalization of serum lipase suggesting that circulating elevated pancreatic lipase level may have contributed to enhanced adipose tissue break down causing ketoacidosis. Therefore, it is believed that ketoacidosis occurring 
With acute pancreatitis or pancreatic ketoacidosis may be mistaken for diabetic ketoacidosis [10-12].

During our treatment as the episode of pancreatitis started to settle down as evidenced by decreasing serum lipase, the ketoacidosis also started to decrease. By the end of 24 hours there were no ketone bodies in plasma and urine; the blood $\mathrm{pH}$ and anion gap returned within normal limits and the abdominal pain had settled. During all this duration his blood glucose were always within normal limits (Table 1, Table 2). Hence in our case it is very clear that acute pancreatitis was itself responsible for this ketoacidosis and it resolved when the patient recovered from the disease.

\section{Conclusion}

Euglycemic KA thus poses a challenge to physicians, as patients presenting with normal BG levels in ketoacidosis may be overlooked, leading to a delay in appropriate management strategies. Despite euglycemia, ketoacidosis in patients remains a medical emergency and must be treated in a quick and appropriate manner.

\section{Reference}

01. Eckerwall G, Olin H, Andersson B, Andersson R. Fluid resuscitation and nutritional support during severe acute pancreatitis in the past- what have we learned and how can we do better?. Clinical Nutrition. 2006;25(3)497-504.

doi: [Article] [Crossref]

02. Kabadi UM. Pancreatic ketoacidosis- ketonemia associated with acute pancreatitis. Postgraduate Med J. 1995;71(831)32-35.

doi: [Article] [Crossref]

03. Kabadi UM. Pancreatic ketoacidosis (kabadi syndrome) mimicking diabetic ketoacidosis. Endocrine Prac. 2015;21(10)1184-1185.

doi: [Article] [Crossref]

04. Prater J, Chaiban JT. Euglycemic diabetic ketoacidosis with acute pancreatitis in a patient not known to have diabetes. AACE Clinic Case Rep. 2015;1(2)e88-e91.

doi: [Article] [Crossref]

05. Rawla P, Vellipuram AR, Bandaru SS, Raj JP. Euglycemic diabetic ketoacidosis- a diagnostic and therapeutic dilemma. Endocrinol, Diab Metabol Case Rep. 2017(1).

doi: [Article] [Crossref]
06. Thawabi M, Studyvin S. Euglycemic diabetic ketoacidosis, a misleading presentation of diabetic ketoacidosis. North Am J Med Sci. 2015;7(6)291-294.

doi: [Article] [Crossref]

07. Modi A, Agrawal A, Morgan F. Euglycemic diabetic ketoacidosis- a review. Curr Diab Rev. 2017;13(3)315-321. doi: [Article] [Crossref]

08. Pillai V. A case of euglycemic pancreatic ketoacidosis-a case report. Univer J Medicine Med Special. 2018;4(2)13-15.

[Crossref]

09. Hurrell FE, Drobatz KJ, Hess RS. Betahydroxybutyrate concentrations in dogs with acute pancreatitis and without diabetes mellitus. J Vet Int Med. 2016;30(3)751-755. doi: [Article] [Crossref]

10. Kabadi UM. Pancreatic ketoacidosis- ketonemia secondary to increased circulating lipase of acute pancreatitis. Diab Res. 1999;34(1)1-7. [Crossref]

11. Kabadi UM. Pancreatic ketoacidosis- Imitator of diabetic ketoacidosis. Int J Diab Develop Count. $1994 ; 14 ; 74-82$.

[Crossref]

12. Kabadi UM. Pancreatic Ketoacidosis- A syndrome mimicking diabetic ketoacidosis. Endocr Pract. 2015;21(10)1184-1185.

doi: [Article] [Crossref] 